\title{
Epidemiological Patterns of Varicella in the Period of 1977 to 2012 in the Rijeka District, Croatia
}

\author{
Vjekoslav Bakašun and Đana Pahor \\ Public Health Institute, 51000 Rijeka, Croatia \\ Correspondence should be addressed to Vjekoslav Bakašun; vjekoslav.bakasun@ri.t-com.hr \\ Received 30 August 2013; Revised 13 November 2013; Accepted 15 December 2013; Published 29 January 2014 \\ Academic Editor: Huibert Burger
}

Copyright ( 2014 V. Bakašun and Đ. Pahor. This is an open access article distributed under the Creative Commons Attribution License, which permits unrestricted use, distribution, and reproduction in any medium, provided the original work is properly cited.

\begin{abstract}
The incidence and distribution of reported varicella cases in the Rijeka District (RD), Croatia (323,130 inhabitants in 1990 and because of the new administrative distribution 305,505 inhabitants in 1991), from 1977 to 2012 are presented. During this period, varicella is continuously present in the RD and these epidemics appear practically every other year. The highest incidence of 1642 per 100,000 inhabitants was registered in 1987. High incidence was also registered during the interepidemic years, while the lowest 247 per 100,000 inhabitants was registered in 2001. Children between the ages of 5 and 9 years were mostly infected, while $87.7 \%$ of the 78,883 registered cases were in those up to 14 years. Varicella manifests most intensively during winter and spring, with a peak in March and April. Males are not significantly more affected (51.1\%) than females (48.9\%). In the observed period, there was not a single reported case of death connected with the varicella disease.
\end{abstract}

\section{Introduction}

Varicella (chickenpox) is generally perceived to be a common contagious predominantly childhood disease with relatively benign morbidity. Children aged 5 to 9 have the highest incidence. It is endemic in large urban centres with superimposed epidemics every 2 to 3 years. Varicella occur all year round, but in temperate climates it is typically more frequent in the late winter and early spring time $[1,2]$.

Varicella did not arouse much attention during earlier years when measles, mumps, and rubella were uncontrolled, and data on its incidence were rarely published. Because vaccination programs have resulted in decreased rates of measles, mumps, and rubella, varicella now ranks as the most common exanthema of childhood. Therefore the control of varicella now draws greater attention. Vaccine has been developed and in the last twenty years it has been used in national childhood vaccination programs in some countries. In Croatia, varicella vaccination has not yet been made a part of the programme of vaccination [1]. The individual varicella vaccination of children is being conducted by certain paediatricians in the private sector, but that data is not available. One can only assume that the number of vaccinated children remains rather insignificant. Showing varicella epidemiological characteristics in the prevaccination period is considered useful, due to their probable changes following the introduction of the vaccine.

The purpose of this paper is to present the epidemiological characteristics of reported cases of varicella in the Rijeka District (RD), Croatia, during the period of 1977 to 2012.

\section{Material and Methods}

The Rijeka District had 321,007 inhabitants in 1990. Because of territorial administrative changes this region has become smaller, and the number of population has been reduced since 1991 (305,505 inhabitants) [3]. Since July 1976 the reporting of varicella cases has become compulsory. It has been done by post on official forms by general practitioners employed in the Health Centres. Until 1991 there was no private primary health care practice, which since then has been introduced. Today about three-quarters of these doctors are practicing it. As the obligation is general, some cases were reported by other doctors (mostly specialists of infectious diseases). As 


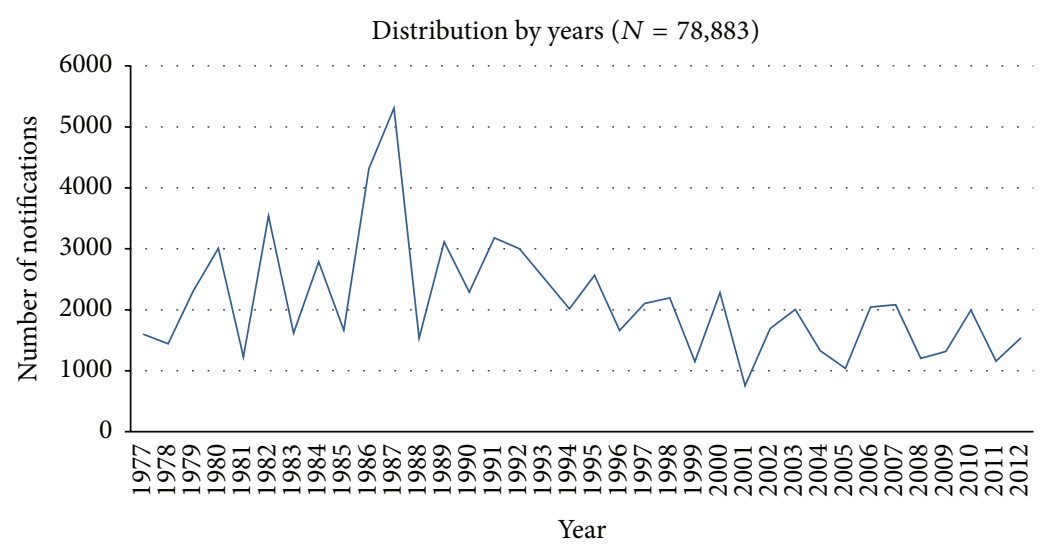

FIGURE 1: Notification of varicella in RD 1977-2012.

registering was introduced in the middle of 1976, the data analysis in this work began with year 1977.

Reporting has been based on clinical symptoms and signs in patients visited by doctors only. The reports were collected and for the period 1977-2012 were processed and analysed by the Department of Epidemiology, Public Health Institute of Rijeka District (PHI). The official statistics do not include the data about hospitalization and complications in varicella patients.

\section{Results}

There were 78,883 cases of varicella reported in the RD during the thirty-five-year period (1977-2012) of observation. The yearly average was 2,254 cases. Figure 1 shows that varicella is continuously present in the area and that epidemics appear practically every other year. The incidence was high during the interepidemic period, too. The lowest incidence of 247 per 100,000 inhabitants was registered in 2001, while the highest incidence of 1,642 per 100,000 was registered in 1987.

Figure 2 shows the number of cases according to month of report for the total period of observation and demonstrates the seasonality of varicella infection. The highest incidence is registered in the winter (peak in January) and spring months (peaks in March and April). The number of registered cases is small during the summer months, while the smallest number is registered during September.

Out of the total of registered cases, $51.1 \%$ were males and $48.9 \%$ were females. The age distribution of the registered cases (Table 1) shows that the highest proportion (41.2\%) was in the age group of 5-9 years, followed by the age group of $0-4$ years $(26.5 \%)$ and age group of $10-14$ years $(20.0 \%)$. The majority of cases-87.7\%-were in the age group of up to 14 years, while $5.3 \%$ of cases were in the age group of 20 years.

Figure 3 gives a more detailed analysis of the registered varicella cases among children and adolescents aged 0-19 years. The cases presented account for $94.7 \%$ of all registered cases. High frequencies are recorded from the age of two till eleven, being highest and almost equal in the age of four, five, and six.
TABLE 1: Age-specific incidence rate of reported varicella cases, $R D$, 1977-2012 $(N=78,883)$.

\begin{tabular}{lcc}
\hline Age group & $\begin{array}{c}\text { Number of } \\
\text { reported cases }\end{array}$ & $\begin{array}{c}\text { Age-specific } \\
\text { incidence rate } \\
0 / 0000\end{array}$ \\
\hline 0 & 552 & 22.0 \\
$1-4$ & 20017 & 200.1 \\
$5-9$ & 30961 & 263.2 \\
$10-14$ & 12402 & 97.7 \\
$15-19$ & 7279 & 52.7 \\
$20-29$ & 3356 & 9.0 \\
$30-39$ & 3095 & 7.7 \\
$40-49$ & 929 & 2.3 \\
$50-59$ & 152 & 0.002 \\
60 and over & 140 & 0.002 \\
\hline
\end{tabular}

In the period under observation not a single case of death connected with varicella disease was reported.

\section{Discussion}

Prior to introduction of compulsory reporting of varicella cases in 1976, epidemiological characteristics and patterns in RD had not been available.

Varicella is the most commonly notified communicable disease as almost everyone is infected before reaching adulthood. The clinical diagnosis of a typical varicella case is simple, and we consider that yet many cases have still not been reported [2]. The number of reported cases depends partly on the legal duty, but also on the attitude of responsible general practitioners. Probably underreporting of the disease is due to it being so mild in many children whose parents recognised it and did not consult the primary health doctor or perhaps sought a consultation for only the index case in a family and not for subsequent cases [4].

In order to achieve better reporting of varicella in the $\mathrm{RD}$, two actions were done. The first is through education. The epidemiologist from the PHI in Rijeka teaches epidemiology 


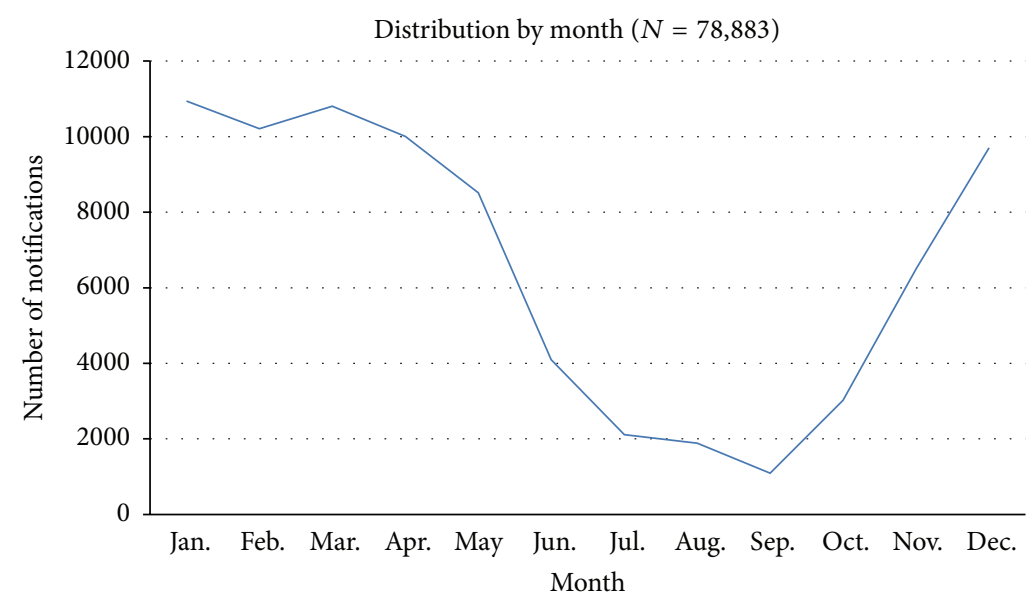

FIGURE 2: Notification of varicella in RD 1977-2012.

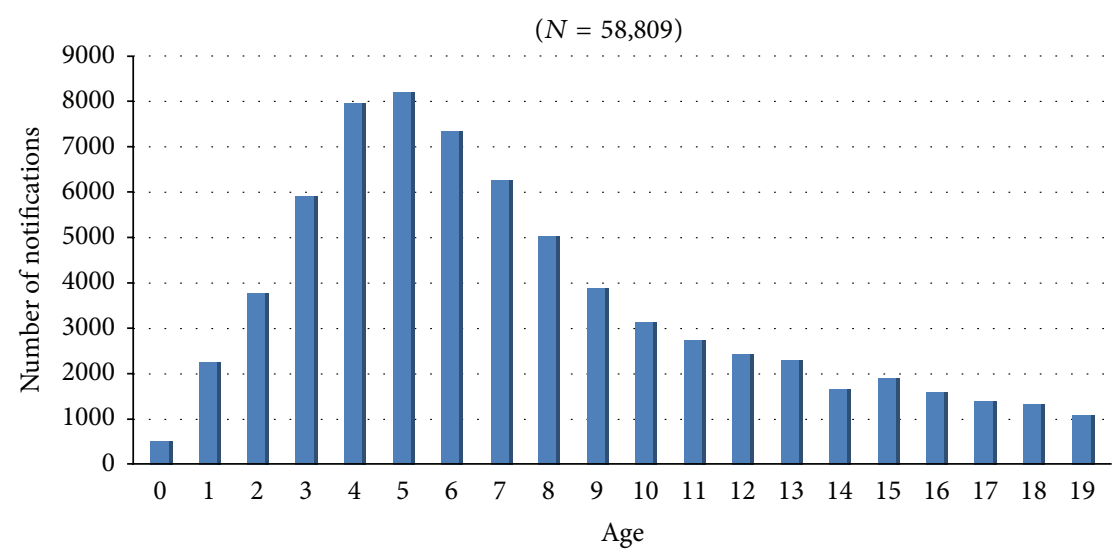

FIGURE 3: Incidence rate of reported varicella cases by the age of 0-19, 1977-2012.

at the Faculty of Medicine, University of Rijeka, where he informs the students about the obligatory reporting of infectious diseases (including varicella). The second is a close cooperation between the Department of Epidemiology of the PHI and general practitioners. The result of such a long period of cooperation is a very good reporting of all infectious diseases.

Because of this, it is assumed that the number of reported cases of varicella in the RD is very close to the actual number of the manifested cases. There were 111,435 children born in $\mathrm{RD}$ during the period of observation (yearly average was 3,183 ), while there were 78,883 registered varicella cases (yearly average was 2,254). Comparing the number of children with the number of registered varicella cases, it can be concluded that $70,8 \%$ (probably even more) of children develop typical symptoms and manifest a clinical form of varicella.

The data in Figure 1 displays the decrease of the number of registered varicella cases in the last twenty years. It cannot be proven, but that is a probable consequence of the privatisation of Primary Health Service after 1993. Those doctors, although required, tend to report in lesser numbers those who are infected with infectious diseases.

According to the data available, varicella is evidently endemically present in the $\mathrm{RD}$, and an epidemic is registered nearly every other year, and interepidemic periods are characterised with relatively high incidences.

Clinical reporting scheme in the $\mathrm{RD}$ ranged from 247 to 1,642 per 100,000 inhabitants, with a yearly average rate of 945 per 100,000 . The average rate is nearly 50 per cent higher, and the maximum is two times higher than the one registered in England and Wales practically in the same period [5] and compared to Slovenia $[6,7]$.

The analysis of the data indicates that on average $0.72 \%$ of the population in RD contract varicella each year. In England and Wales this average was $0.5 \%$ in the same period [5].

Varicella is most frequent in this area during the winter and spring months, that is a typically seasonal distribution in the temperate zone. A considerable fall in the registered cases during February is believed to be due to the fact that this month is three days shorter than the two immediately preceding and following it. It is also a result of the winter 
school holidays in $\mathrm{RD}$, which temporarily break the chain of infections in schools. However, the exclusion from class of the sick, once the disease appeared, did not break the chain of infection.

There is very small prevalence $(1.04: 1.0)$ of registered cases in males compared to females. The same was noted by other authors as well $[1,5]$.

The highest incidence of infection is between the ages of 5 and 9 years, which is a known characteristic of varicella [1, 2]. There were $87.7 \%$ of cases registered in the $0-14$-year age group. This conforms with the findings elsewhere $[1,2,8-10]$. A detailed observation according to age in the $\mathrm{RD}$ shows that the most affected are preschool children in the fourth, fifth, and sixth year of life. It can be explained by the fact that many children of that age attend kindergartens, so that starting the elementary school does not represent a greater stimulus for the spreading of the disease.

Officially, there have been no reported cases of varicella related deaths. The authors will do a follow-up research and try to get a hold of the hospital documentation and verify this data.

To conclude, one can only question oneself. In the light of the fact that the varicella were uniformly not serious, one can ask oneself whether or not there are any reasons to use a vaccine to prevent it. After all, the natural immunity acquired by overcoming varicella leaves behind a lifelong immunity. The time span from the introduction of the vaccine has been too short to determine the duration of the immunity acquired by vaccination. Only the decades to follow will be showing the success of the vaccines used for varicella prevention.

\section{Conflict of Interests}

The authors declare that there is no conflict of interests regarding the publication of this paper.

\section{References}

[1] R. J. Whitney, "Varicella-zoster virus," in Principles and Practice of Infectious Diseases, G. L. Mandell, J. E. Bennett, and R. Dolin, Eds., pp. 1963-1969, Churchill Livingstone Elsevier, 7th edition, 2010.

[2] S. R. Preblud, W. A. Orenstein, and K. J. Bart, "Varicella: clinical manifestations, epidemiology and health impact in children," Pediatric Infectious Disease, vol. 3, no. 6, pp. 505-509, 1984.

[3] Anonimus, Zdravstveno-Statistički Ljetopis Primorsko-Goranske Županije Za 2012, Zavod za Javno Zdravstvo Rijeka, Rijeka, Croatia, 2013.

[4] R. E. Hote-Simpson, "Infectiousness of communicable diseases in the household (measles, chickenpox, and mumps)," The Lancet, vol. 2, no. 12, pp. 549-554, 1952.

[5] C. A. Joseph and N. D. Noah, "Epidemiology of chickenpox in England and Wales, 1967-85," British Medical Journal, vol. 296, no. 6623, pp. 673-676, 1988.

[6] M. Sočan, A. Kraigher, and L. Pahor, "Epidemiology of varicella in Slovenia over a 20-year period (1979-98)," Epidemiology and Infection, vol. 126, no. 2, pp. 279-283, 2001.

[7] M. Socan and M. Blaško, "Surveillance of varicella and herpes zoster in Slovenia, 1996 -2005," Eurosurveillance, vol. 12, pp. 1316, 2007.
[8] S. Deguen, N. P. Chau, and A. Flahault, "Epidemiology of varicella in France (1991-1995)," Journal of Epidemiology and Community Health, vol. 52, supplement 1, pp. 46S-49S, 1998.

[9] J. C. Bramley and I. G. Jones, "Epidemiology of chickenpox in Scotland: 1981 to 1998," Communicable Disease and Public Health, vol. 3, no. 4, pp. 282-287, 2000.

[10] A. M. Ross and D. M. Fleming, "Chickenpox increasingly affects preschool children," Communicable Disease and Public Health, vol. 3, no. 3, pp. 213-215, 2000. 


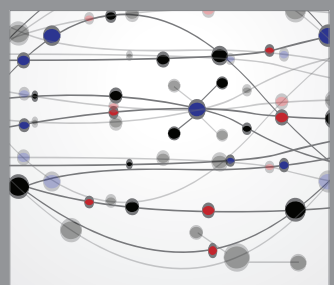

The Scientific World Journal
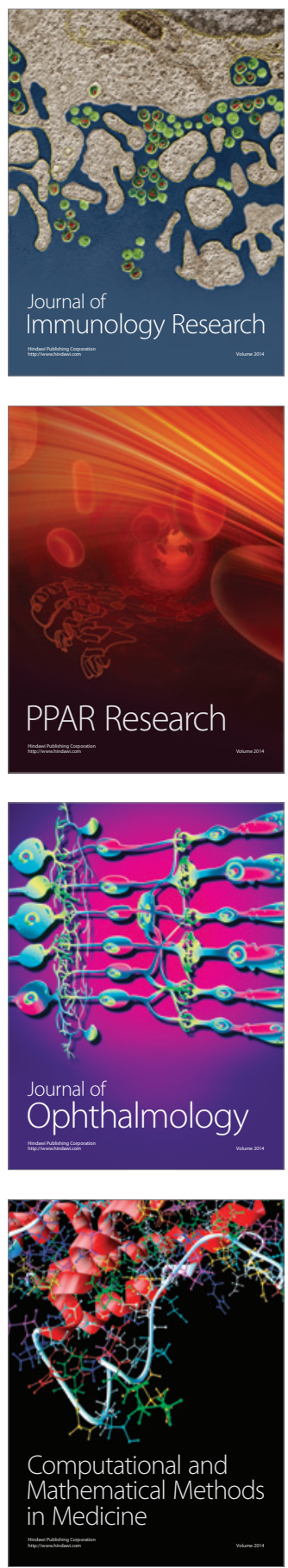

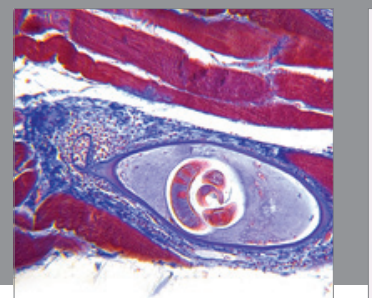

Gastroenterology

Research and Practice
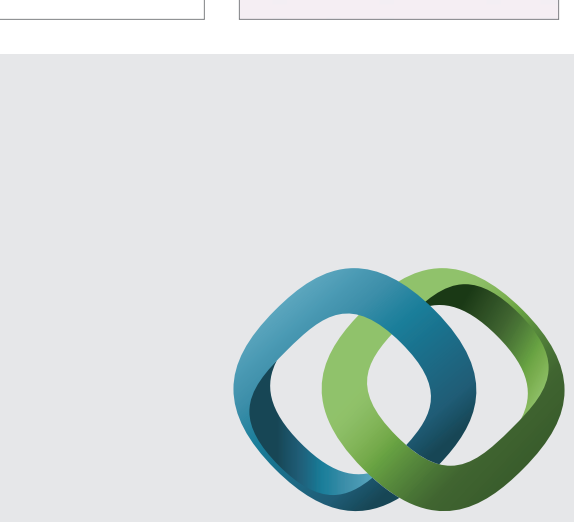

\section{Hindawi}

Submit your manuscripts at

http://www.hindawi.com
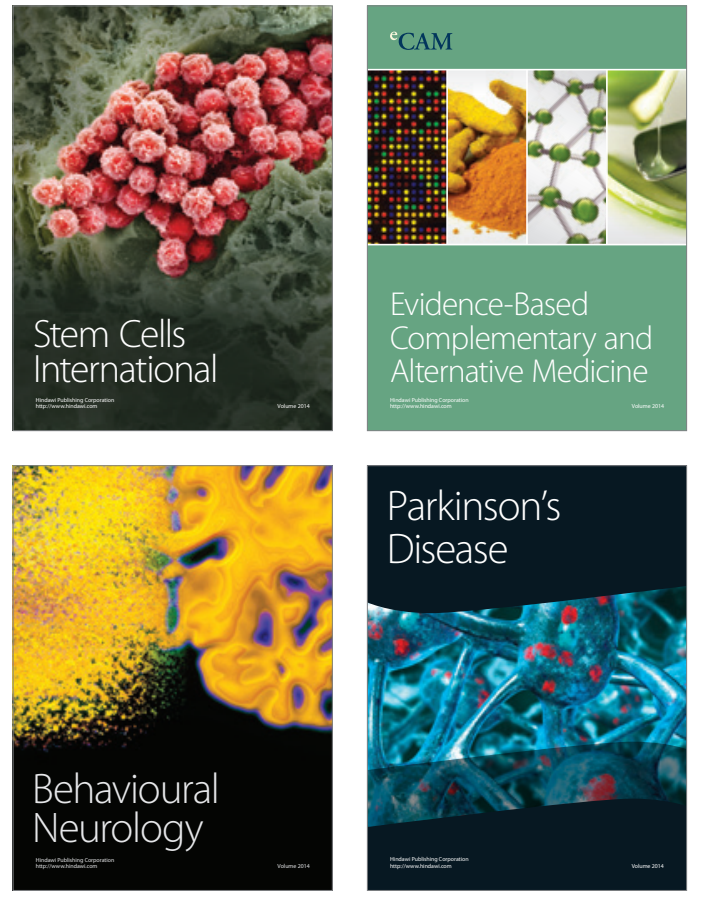
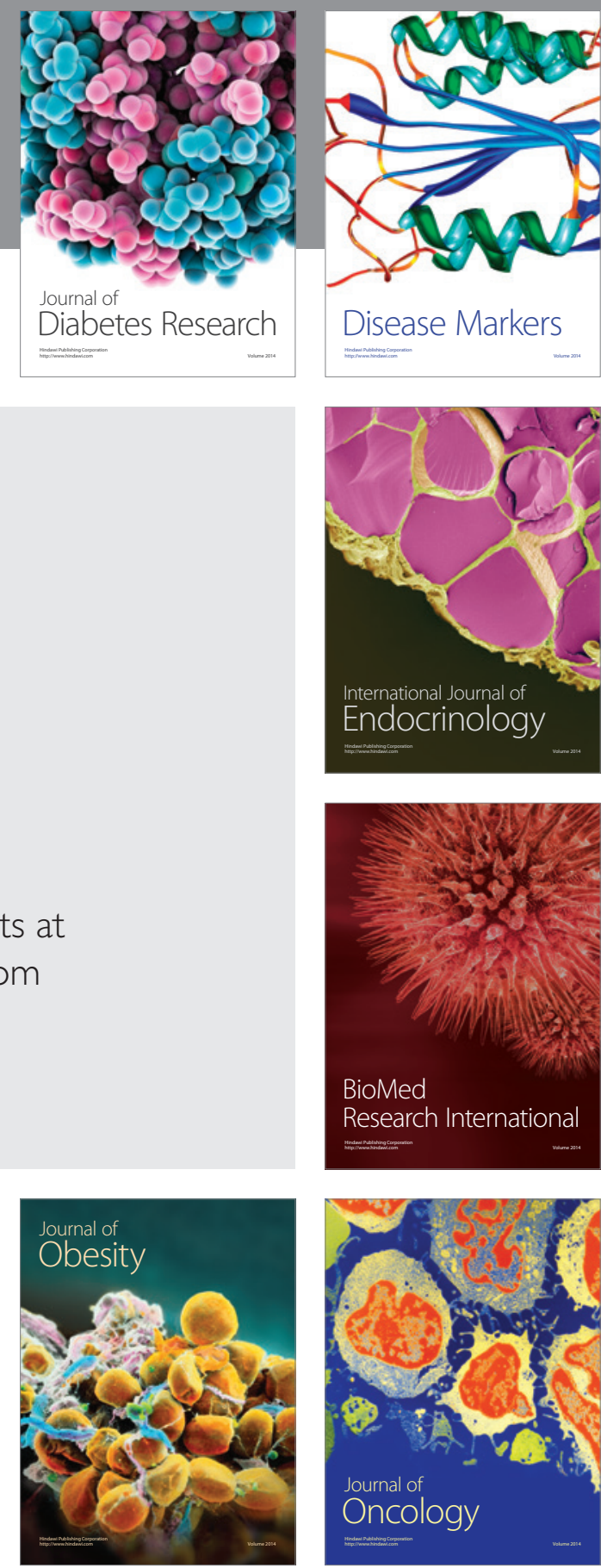

Disease Markers
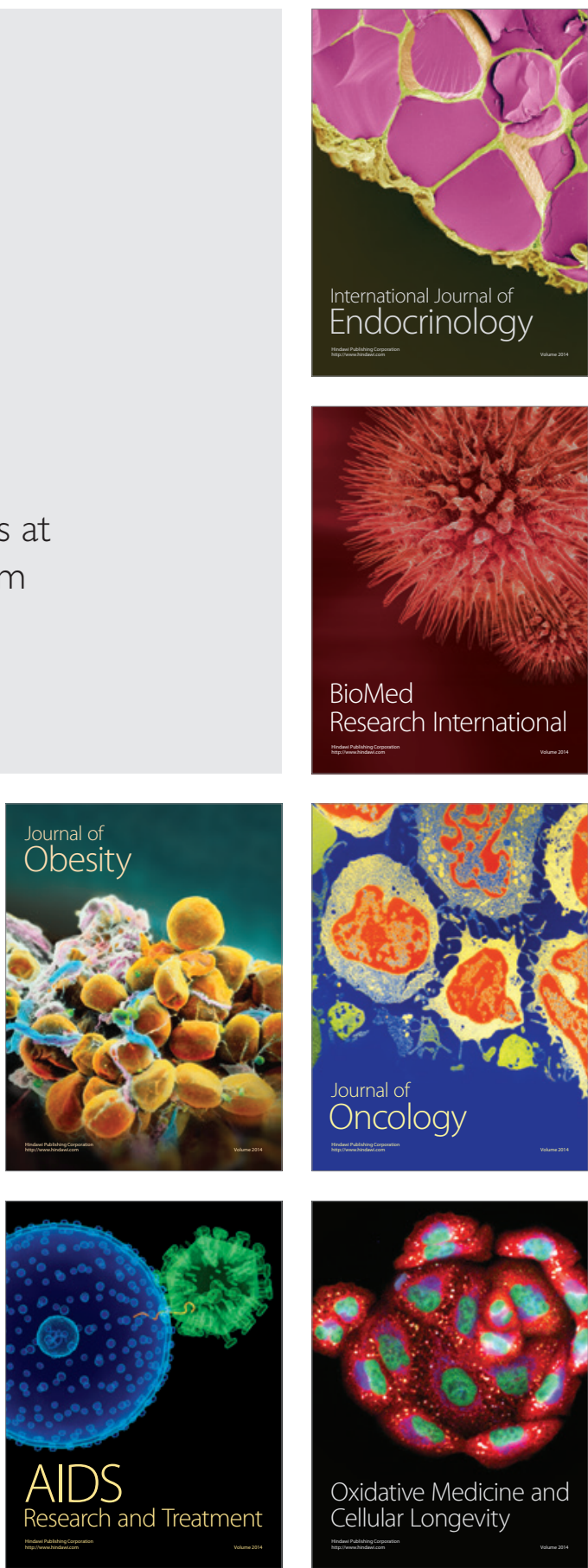